\title{
Characterization of Tris (5-amino-1,10-phenanthroline) Ruthenium(II/III) Polymer Films Using Cyclic Voltammetry and Rutherford Backscattering Spectrometry
}

\author{
Kenneth L. Brown (Corresponding author), Xisen Hou, Olajide Banks, Kevin A. Krueger \\ Julian Hinson, Graham F. Peaslee \& Paul A. DeYoung \\ Department of Chemistry and Physics, Hope College \\ 35 East $12^{\text {th }}$ Street \\ Holland, Michigan 49424, USA
}

Tel: 1-616-395-7173 E-mail: brownk@hope.edu

\author{
Shannon M. Alger, Jessica Benzer \& Thomas L. Neils \\ Physical Sciences Department \\ 143 Bostwick Avenue \\ Grand Rapids, Michigan 49503, USA
}

Tel: 1-616-234-4219Ｅ-mail: tneils@grcc.edu

Received: July 14, 2011

Accepted: August 10, $2011 \quad$ Published: December 1, 2011

doi:10.5539/ijc.v3n4p12

URL: http://dx.doi.org/10.5539/ijc.v3n4p12

\begin{abstract}
Platinum electrodes were chemically modified with tris(5-amino-1,10-phenanthroline) ruthenium(II) via electropolymerization. The characterization of the thin films was accomplished with cyclic voltammetry (CV) and Rutherford Backscattering Spectrometry (RBS). Data indicates a strong correlation between the peak currents from the characterization cyclic voltammograms and the number of cycles of electropoly-merization. Rutherford Backscattering Spectrometry showed the same trend, and verified that film thickness is strongly dependent on the concentration of the monomer ruthenium solution. Film thickness was determined from the change in ion beam energy as it passed through the film and was calculated to be $1.0 \times 10^{18}$ atoms $/ \mathrm{cm}^{2}-3.4 \mathrm{x}$ $10^{18}$ atoms $/ \mathrm{cm}^{2}$, depending upon the number of electropolymerization cycles. The electrodes also showed differences in surface roughness, which were dependent on film thickness.
\end{abstract}

Keywords: Electropolymerization, Rutherford Backscattering Spectrometry, Cyclic Voltammetry

\section{Introduction}

Chemically modified electrodes continue to be a focus in a number of electrochemical applications. These electrodes can be prepared from electronically conducting polymers, redox polymers, and loaded ionomers (Abruna et al., 1981; Brown et al., 1998; Pinter et al., 2007; Ellis et al., 1983; Calvert et al., 1983; Guarr et al., 1987). In each of these examples, the electrodes function to catalyze electrochemical reactions, improve electrode stability, and help develop electrochemical sensors and biosensors. Since the work done by Lane and Hubbard (Lane et al., 1973) involving the use of chemisorbed metals on platinum electrode surfaces, numerous methods have been developed to anchor compounds on various electrode materials. Some of the different methods of compound immobilization and electrode functionalization include spin coating, covalent attachment, and electropolymerization (Brown et al., 2002). This research focuses on the chemical modification of platinum electrodes via electropolymerization and characterization of the derived films using CV and RBS (Baum et al., 1991; Huang et al., 1992; Ramana et al., 2005; Lee et al., 2006; Walters et al., 2008; Goudarzi et al., 2009; Niesen et al., 2001). Several research groups have reported on the electropolymerization of tris(5-amino-1,10-phenanthroline) iron(II) and ruthenium(II) complexes (Ellis et al., 1983; Ren et al., 1994); platinum electrodes used in our work have been modified with a ruthenium complex of 5-amino-1,10-phenanthroline, $\left.\left(\mathrm{Ru}(5 \text {-phenNH})_{3}\right)_{3}\right)\left(\mathrm{PF}_{6}\right)_{2}$. The motivation for using this compound is related to our 
continuing efforts to develop spectroelectrochemical sensors for hydrazine in which the ruthenium complex functions as an electrocatalyst in the detection of hydrazine (Pinter et al., 2007).

The modification of the platinum electrodes was accomplished using $\mathrm{CV}$, which is one of the most versatile electroanalytical techniques used to characterize electroactive species. The amount of material deposited on the electrode surface was controlled by the number of cycles completed. It should also be mentioned that other factors such as scan rate, potential window, and concentration of electroactive species can affect film thickness; the impact of monomer concentration on film thickness is addressed in this paper. In the development of electrochemical sensors based on polymer films, film thickness can play a critical role in the kinetics of charge transfer (Kaufman et al., 1980). Hence, it becomes important to have a versatile method that can determine film thicknesses. There are several methods that can be used to determine film thickness and this paper reports on the use of RBS to determine film thicknesses of films prepared under different solution conditions. Peak currents from cyclic voltammetric data are correlated to surface coverage data acquired using RBS. In addition, qualitative characteristics about the polymer film were gained through RBS and were related to the cyclic voltammetric data about the films.

\section{Experimental}

\subsection{Reagents and Solutions}

The ruthenium complex, $\left(\mathrm{Ru}\left(5-\mathrm{phenNH}_{2}\right)_{3}\right)\left(\mathrm{PF}_{6}\right)_{2}$, shown in Figure 1 was prepared by Neils and co-workers according to published procedures (Ellis et al., 1983). The acetonitrile used as the solvent for all electrochemical studies was obtained from Sigma Aldrich. The tetraethylammonium perchlorate (TEAP) was purchased from GFS Chemicals and was used as the supporting electrolyte. To remove trace amounts of water, the TEAP was dried over vacuum and stored in a desicator. In the initial experiments, the concentrations of the ruthenium complex and TEAP were $1.00 \times 10^{-3} \mathrm{M}$ and $0.100 \mathrm{M}$, respectively. To evaluate the effect of concentration on the thickness of the films, $5.00 \times 10^{-4} \mathrm{M}$ and $0.050 \mathrm{M}$ solutions of the ruthenium complex and TEAP, respectively, were also prepared and used in the electropolymerizations.

\subsection{Instrumentation}

The ruthenium complex was characterized using ${ }^{1} \mathrm{H}$ NMR and IR. The ${ }^{1} \mathrm{H}$ NMR spectra were obtained with a Varian Mercury $400 \mathrm{MHz}$ spectrophotometer. Dimethylsulfoxide ( $\mathrm{d}_{6}$-DMSO) was used as the solvent in all characterization measurements for ${ }^{1} \mathrm{H}$ NMR. Infrared spectra via $\mathrm{KBr}$ pellets were obtained using an M-Series FT-IR from MIDAC Corporation. All electropolymerizations and other cyclic voltammetric measurements were performed with a CHInstruments 601A electrochemical analyzer (CHInstruments, Inc., Austin, TX, USA). The three-electrode cell consisted of a platinum working electrode, a glassy carbon auxiliary electrode (diameter $=3$ $\mathrm{mm})$, and a $\mathrm{Ag} / \mathrm{AgCl}(3 \mathrm{M} \mathrm{NaCl})$ reference electrode. All electrodes were acquired from CHInstruments.

Rutherford backscattering measurements were conducted at the Hope College Ion Beam Analysis Lab using a 5-SDH Tandem Pelletron (National Electrostatics Corporation, Middleton, WI, USA). All the RBS measurements were performed using a $2.9 \mathrm{MeV} \mathrm{He}^{+}$ion beam. The targets were mounted parallel to the ion beam in a specially engineered steel sample holder and the beam was collimated to a position approximately 1 $\mathrm{mm}$ in diameter. A surface barrier detector with a FWHM resolution of $24 \mathrm{KeV}\left({ }^{148} \mathrm{Gd}, 3.18 \mathrm{MeV}\right)$ was located approximately $11 \mathrm{~cm}$ from the target at a $162.5^{\circ}$ angle with respect to the beam. A mixed source $\left({ }^{148} \mathrm{Gd},{ }^{239} \mathrm{Pu}\right.$, ${ }^{241} \mathrm{Am},{ }^{244} \mathrm{Cm}$ ) was used to ensure an absolute energy marker for all resulting spectra. Each target was irradiated for 10 minutes with approximately $1 \mathrm{nA}$ of beam current to minimize damage to the film. Data analysis was performed using the SIMNRA program. Our previous research involving RBS utilized the RUMP software for data analysis and simulations.

\subsection{Procedure for Electropolymerization and Electrochemical Characterization of Thin Films}

Prior to all electrochemical measurements, the working electrode was polished with $0.05 \mu \mathrm{m}$ alumina on a wet polishing pad. This was done by placing several drops of the alumina on the polishing pad and moving the electrode in a circular motion across the surface of the polishing pad. The electrodes were then rinsed with water purified by reverse osmosis, sonicated for 5 minutes, and dried under nitrogen gas. All solutions were purged with $\mathrm{N}_{2}$ gas for 15 minutes and a $\mathrm{N}_{2}$ blanket was maintained over the solutions during all measurements. The electropolymerizations were performed using a potential window of $1.800 \mathrm{~V}$ to $0.800 \mathrm{~V}$ at a scan rate of 0.050 $\mathrm{V} / \mathrm{sec}$. The amount of material deposited on the electrode surface was controlled by the number of electropolymerization cycles. The electrodes were characterized in the supporting electrolyte solution using a potential window of $1.800 \mathrm{~V}$ to $0.800 \mathrm{~V}$ and a scan rate of $0.010 \mathrm{~V} / \mathrm{sec}$. 


\section{Results and Discussion}

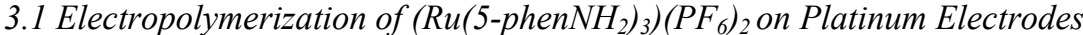

Characterization of the ruthenium complex, using ${ }^{1} \mathrm{H}$ NMR, showed integration of signals confirming the presence of 27 protons. Protons associated with the 5-amino-1,10-phenanthroline ligand displayed chemical shifts in the range of 6.90-8.50 ppm. The protons specific to the phenanthroline aromatic system were present from 7.50-9.00 ppm. Infrared spectra revealed the presence of the -amino group, $\mathrm{NH}_{2}$ stretching, at $3401 \mathrm{~cm}^{-1}$.

The electropolymerization of the ruthenium complex in Figure 1 is based on the irreversible oxidation of the amine substituent which produces radical cations (Figure 2) and subsequent follow-up chemical reactions of the radical cations produces the polymer film. The electropolymerization of this compound and similar compounds have been reported in the literature. Figure 3 shows cyclic voltammograms corresponding to twenty cycles of electropolymerization of the ruthenium complex. The increase in the peak currents for each cycle indicates that material was deposited on the electrode surface. The redox couple at $\mathrm{E}^{\mathrm{o}}=1.540 \mathrm{~V}$ is related to the following process:

$$
\text { (5-phen- } \left.\mathrm{NH}_{2}\right)_{3} \mathrm{Ru}(\mathrm{II}) \leftrightarrows\left(5-\text { phen- } \mathrm{NH}_{2}\right)_{3} \mathrm{Ru}(\mathrm{III})+\mathrm{e}^{-}
$$

The formal reduction potential was calculated using:

$$
\left(\mathrm{E}_{\mathrm{pa}}+\mathrm{E}_{\mathrm{pc}}\right) / 2
$$

where $E_{p a}$ and $E_{p c}$ represent the peak potentials of the anodic and cathodic processes, respectively. Visual inspection of the electrode surface revealed an orange color, which increased in intensity as the number of electropolymerization cycles increased. The anodic peak initially at ca. $1.290 \mathrm{~V}$ corresponds to an oxidation prewave, which shifts to more positive potentials as the electropolymerization process continues, whereas the predominant anodic peak and cathodic peaks shift only modestly. As the electropolymerization process continues, this prewave peak eventually merges with the other anodic peak at ca. $1.580 \mathrm{~V}$. The current response of each electropolymerization cycle for the $1.00 \times 10^{-3} \mathrm{M}$ and $5.00 \times 10^{-4} \mathrm{M}$ ruthenium complex solutions gave slopes of $4.1 \pm 0.1 \mu \mathrm{A} /$ cycle and $2.2 \pm 0.2 \mu \mathrm{A} /$ cycle for the anodic and cathodic processes respectively. It is worth mentioning is that as the electropolymerization proceeds beyond thirty cycles, the peak currents come to a steady state due to increasing electrode coverage with the ruthenium complex with this effect being more prevalent in the higher concentration solution.

\subsection{Electrochemical Behavior of $\left(\mathrm{Ru}\left(5-\text { phenN }_{2}\right)_{3}\right)\left(\mathrm{PF}_{6}\right)_{2}$ Polymer Films}

Representative cyclic voltammograms of the polymer film characterization in the supporting electrolyte solution corresponding to 5, 10, and 20 cycles of electropolymerization are shown in Figure 4. The cathodic and anodic peaks are a result of electron "hopping" between redox centers, corresponding to the surface bound process of equation 1. The formal reduction potential for peaks in cyclic voltammogram (A) of Figure 4 is $1.529 \mathrm{~V}$. The respective $\mathrm{E}^{\mathrm{o}}$, values for redox couples $(\mathrm{B})$ and $(\mathrm{C})$ are $1.515 \mathrm{~V}$ and $1.520 \mathrm{~V}$. Charge electroneutrality must be maintained by charge compensating ions, either $\left(\mathrm{CH}_{3} \mathrm{CH}_{2}\right)_{4} \mathrm{~N}^{+}$or $\mathrm{ClO}_{4}{ }^{-}$from the supporting electrolyte solution, entering or leaving the polymer film. Moreover, the compensating ions are accompanied by solvent shells, which cause solvent pockets to develop within the film, thereby forcing the polymer film to swell. Peak separation $\left(\Delta \mathrm{E}_{\mathrm{p}}\right)$ for redox couple (A) is $0.020 \mathrm{~V}$, which is close to the theoretical value of zero peak separation for surface bound species. These results indicate Nernstian equilibrium conditions of the $\mathrm{Ru}(\mathrm{II} / \mathrm{III})$ redox sites relative to the scan rate. As the thickness of the films increase, the respective $\Delta \mathrm{E}_{\mathrm{p}}$ values increase and the system transitions from reversible to quasireversible; redox couples (B) and (C) have $\Delta \mathrm{E}_{\mathrm{p}}$ values of $0.044 \mathrm{~V}$ and $0.095 \mathrm{~V}$, respectively. At high scan rates, the peak separation increases due to kinetic limitations of the charge transfer process. In addition, $\mathrm{E}^{\mathrm{o}}$, for $\mathrm{Ru}(\mathrm{II} / \mathrm{III})$ for the films is approximately equal to $\mathrm{E}^{\mathrm{o}}$, for the solution. However, the peak width at half height is greater than the predicted $90.6 \mathrm{mV}$ because of non-equivalent redox sites, $\mathrm{Ru}(\mathrm{II} / \mathrm{III})$, or attractive/repulsive forces within the film (Peerce et al., 1980). Unequal distribution of redox sites, solvent pockets, or ion content within the polymer film, results in non-equivalent redox centers throughout the polymer film. The polymer film is essentially a three-dimensional network of redox sites with different lateral and vertical distributions. Although cyclic voltammetry is not capable of differentiating between the two types of distributions, RBS measurements permit the ability to distinguish between these distributions of redox sites within the polymer film. Furthermore as the film thickness increases, $\Delta \mathrm{Ep}$ increases slightly even when the scan rate is constant. The anodic and cathodic peak currents in Figure 5 were obtained using the characterization cyclic voltammograms and come to a steady state at between 30-35 cycles of electropolymerization for the lower concentration of ruthenium complex. 


\subsection{Surface Coverage by RBS}

Since Pt has a higher atomic number than all the elements in the ruthenium-based film, the RBS spectrum shows a single broad peak in Figure 6. The data was fit manually using SIMNRA program. In Figure 6, the solid line represents the 10-cycle data, and the edge to the left represents the 25-cycle data. In RBS, alpha particles lose energy when passed through a film and the amount of energy lost is dependent on the thickness of the film, which causes the front edge of the peak to shift left. As a result, the front edge of the 25 -cycle data is at a lower energy than the 10-cycle data.

Figure 7 shows the variation of film thickness $\left(\right.$ atoms $\left./ \mathrm{cm}^{2}\right)$ with the electropolymerization cycles. The thickness of the film increases as the number of cycles increases and then begins to level off. The more concentrated monomer ruthenium solution shows a less linear increase and starts to level off sooner than the less concentrated monomer ruthenium solution. This is because surface roughness, which is greater when films are prepared from the higher concentration of ruthenium monomer solution, factors into the film thickness. The decrease in ruthenium monomer concentration decreases the surface roughness but also leads to less material deposited on the electrode surface. In addition, films with greater roughness and thickness are more fragile than thinner films. Cyclic voltammetric data also show a leveling out profile that is consistent with RBS data. With respect to the number of electropolymerization cycles, the $1.00 \times 10^{-3} \mathrm{M}$ ruthenium monomer solution gives film thicknesses ranging from $1.0 \times 10^{18}$ atoms $/ \mathrm{cm}^{2}-5.5 \times 10^{18}$ atoms $/ \mathrm{cm}^{2}$ and the $5.00 \times 10^{-4} \mathrm{M}$ ruthenium solution gives film thicknesses ranging from $1.0 \times 10^{18}$ atoms $/ \mathrm{cm}^{2}-3.4 \times 10^{18}$ atoms $/ \mathrm{cm}^{2}$. Visual examination of the electrodes after ion beam irradiation showed no visible effects of damage. However, cyclic voltammetric analysis of films showed a $23 \%$ decrease in peak currents after ion beam irradiation, indicating that the films were damaged by the beam.

\section{Conclusion}

The relationship between the peak currents from the characterization cyclic voltammograms and the number of cycles of electropolymerization shows a good correlation. Rutherford Backscattering Spectrometry shows the same trend and also verifies that film thickness varies with the concentration of monomer solution. In addition, surface roughness is different among the various films and the factors into film thickness measurements. It is clear that the polymer may not grow homogeneously during the electropolymerization process and this may contribute to differences in surface roughness. The ability to observe the changes in the ion bean energy during RBS measurements permits the evaluation of the thin film thickness based on electropolymerization conditions. This was based on determining the amount of the shift in the front edge of the RBS spectra.

\section{Acknowledgements}

This research was supported by the following grants: CHE NSF-URC Grant \#0629174, CHE NSF-REU Grant \#0851194, CHE NSF-S-STEM Grant \#0728574.

\section{References}

Abruna, H.D., Denisevich, P., Umana, M., Meyer, T.J., \& Murray, R.W. (1981). Rectifiying Interfaces Using Two-Layer Films of Electrochemically Polymerized Vinylpyridine and Vinylbipyridine Complexes of Ruthenium and Iron on Electrodes. J. Am. Chem. Soc., 103, 1-5. http://dx.doi.org/10.1021/ja00391a001

Baum, E.M., Li, H., Guarr, T.F., \& Robertson, J.D. (1991). Characterization of Electrochemically Polymerized Metal Phthalocyanines Using Rutherford Backscattering Spectrometry. Nucl. Instrum Methods, B56-57, 761-763. http://dx.doi.org/10.1016/0168-583X(91)95021-5

Brown, K., \& Mottola, H. (1998). Voltammetric, Chronocoulometric and Spectroelectrochemical Studies of Electropolymerized Films Based on $\mathrm{Cu}(\mathrm{II} / \mathrm{I})-4,9,16,23$-tetraaminophthalocyanine. Langmuir, 14, 3411-3417. http://dx.doi.org/10.1021/la9706911

Brown, K., Shaw, J., Ambrose, M., \& Mottola, H. (2002). Voltammetric, Chronocoulometric and Spectroelectrochemical Studies of Electropolymerized Films Based on $\mathrm{Co}$ (III/II)- and $\mathrm{Zn}$ (II) 4,9,16,23-tetraaminophthalocyanine: Effect of High pH. Microchemical Journal, 72, 285-298. http://dx.doi.org/10.1016/S0026-265X(02)00042-5

Calvert, J.M., Schemehl, R.H., Sullivan, B.P., Facci, J.S., T.J. Meyer, \& Murray, R.W. (1983). Synthetic and Mechanistic Investigations of the Reductive Electrochemical Polymerization of Vinyl-Containing Complexes of Iron(II), Ruthenium(II), and Osmium(II). Inorg. Chem., 22, 2151-2162. http://dx.doi.org/10.1021/ic00157a013 
Ellis, C.D., Margerum, L.D., Murray, R.W., \& Meyer, T.J. (1983). Oxidative Electropolymerization of Polypyridyl Complexes of Ruthenium. Inorganic Chemistry, 22, 1283-1291. http://dx.doi.org/10.1021/ic00151a005

Goudarzi, A., Aval, G. M., Park, S. S., Choi, M, Sahraei, R., Ullah, M. H., Avane, A., \& Ha, C. (2009). Low-Temperature Growth of Nanocrystalline Mn-Doped ZnS Thin Films Prepared by Chemical Bath Deposition and Optical Properties. Chem. Mate., 21, 2375-2385. http://dx.doi.org/10.1021/cm803329w

Guarr, T.F., \& Anson F.C. (1987). Electropolymerization of Bis(1,10-phenanthroline) (4-methyl-4'-vinyl-2, 2'-bipyridine) Complexes Through Direct Attack on the Ligand Ring System. J. Phys. Chem., 91, 4037-4043. http://dx.doi.org/10.1021/j100299a022

Huang, J., \& Wrighton, M. (1992). Use of Rutherford Backscattering Spectroscopy to Investigate Anion Exchange Constants of Protonated Poly(4-vinylpyridine). Chem. Mater., 4, 284-290. http://dx.doi.org/10.1021/cm00020a013

Kaufman, F.B., Schroeder, A.H., Engler, E.M., Kramer, S.R., \& Chambers, J.Q. (1980). Ion and Electron Transport in Stable, Electroactive Tetrathiafulvalene Polymer Coated Electrodes. J. Am. Chem. Soc., 102(2), 483-488. http://dx.doi.org/10.1021/ja00522a007

Lane, R.F., \& Hubbard, A.T. (1973). Electrochemistry of Chemisorbed Molecules. I. Reactants Connected to Electrodes Through Olefinic Substituents. J. Phys. Chem., 77, (11), 1401-1410. http://dx.doi.org/10.1021/j100630a018

Lee, W. P., Gundabala, V. R., Akpa, B. S., Johns, M. L., Jeynes, C., \& Routh, A. F. (2006). Distribution of Surfactants in Latex Films: A Rutherford Backscattering Study. Langmuir, 22, 5314-5320. http://dx.doi.org/10.1021/la0601760

Niesen, T. P., Bill, J., \& Aldinger, F. (2001). Deposition of Titania Thin Films by a Peroxide Route on Different Functionalized Organic Self-Assembled Monolayers. Chem. Mater., 13, 1552-1559. http://dx.doi.org/10.1021/cm001227w

Peerce, P.J., \& Bard, A.J. (1980). Polymer Films on Electrodes: Part II. Film Structure and Mechanism of Electron Transfer with Electrodeposited Poly(Vinylferrocene). J. Electroanal Chem., 112, 97-115. http://dx.doi.org/10.1016/S0022-0728(80)80011-8

Pinter, J.S., Brown, K.L., DeYoung, P.A., \& Peaslee, G.F. (2007). Amperometric Detection of Hydrazine by Cyclic Voltammetry and Flow Injection Analysis Using Ruthenium Modified Glassy Carbon Electrodes. Talanta, 71, 1219-1225. http://dx.doi.org/10.1016/j.talanta.2006.06.017

Ramana, C. V., Smith, R. J., Hussain, O. M., Chusuei, C. C., \& Julien, C. M. (2005). Correlation Between Growth Conditions, Microstructure, and Optical Properties in Pulsed-Laser-Deposited $\mathrm{V}_{2} \mathrm{O}_{5}$ Thin Films. Chem. Mater., 17, 1213-1219. http://dx.doi.org/10.1021/cm048507m

Ren, X., \& Pickup, P.G. (1994). Strong Dependence of the electron-hopping rate in Poly-tris(5-amino-1, 10-phenanthroline) iron (III/II) on the Nature of the Counter-Anion. J. of Electroanal Chem., 365, 289-292. http://dx.doi.org/10.1016/0022-0728(93)03052-Q

Walters, R. M., Taubert, A., Kim, J., Winey, K. I., \& Composto, R. J. (2008). Surface Segregation of Counterions in Ionomer Films. Macromolecules, 41, 9299-9305. http://dx.doi.org/10.1021/ma801756g

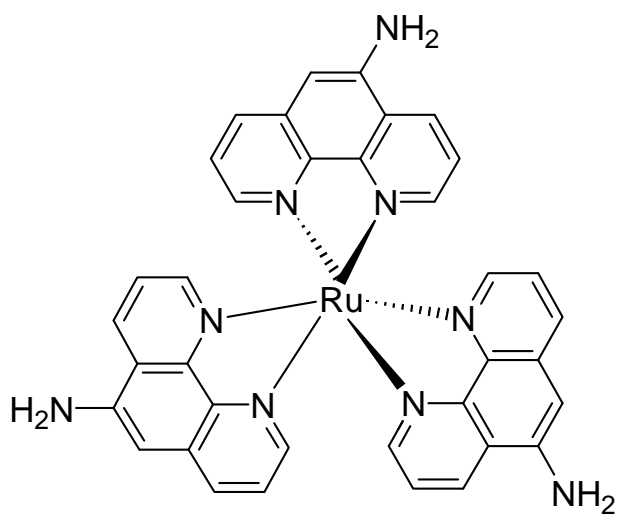

Figure 1. Structure of Tris(5-amino-1,10-phenanthroline) Ruthenium(II) 
<smiles>Nc1cc2cccnc2c2ncccc12</smiles>

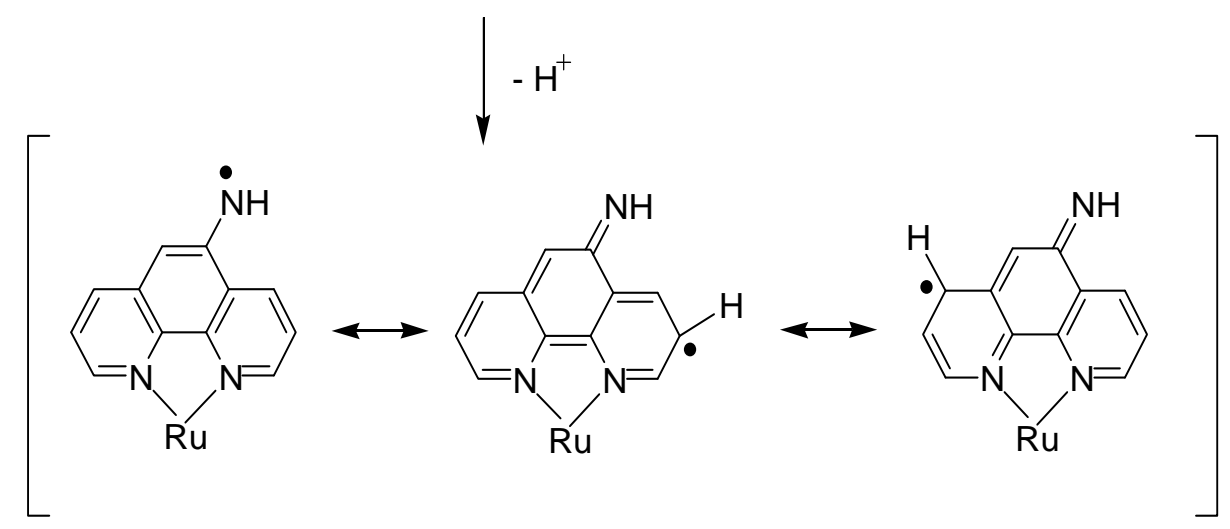

Figure 2. Reactions showing the initial oxidation of the ligand leading to the polymer film

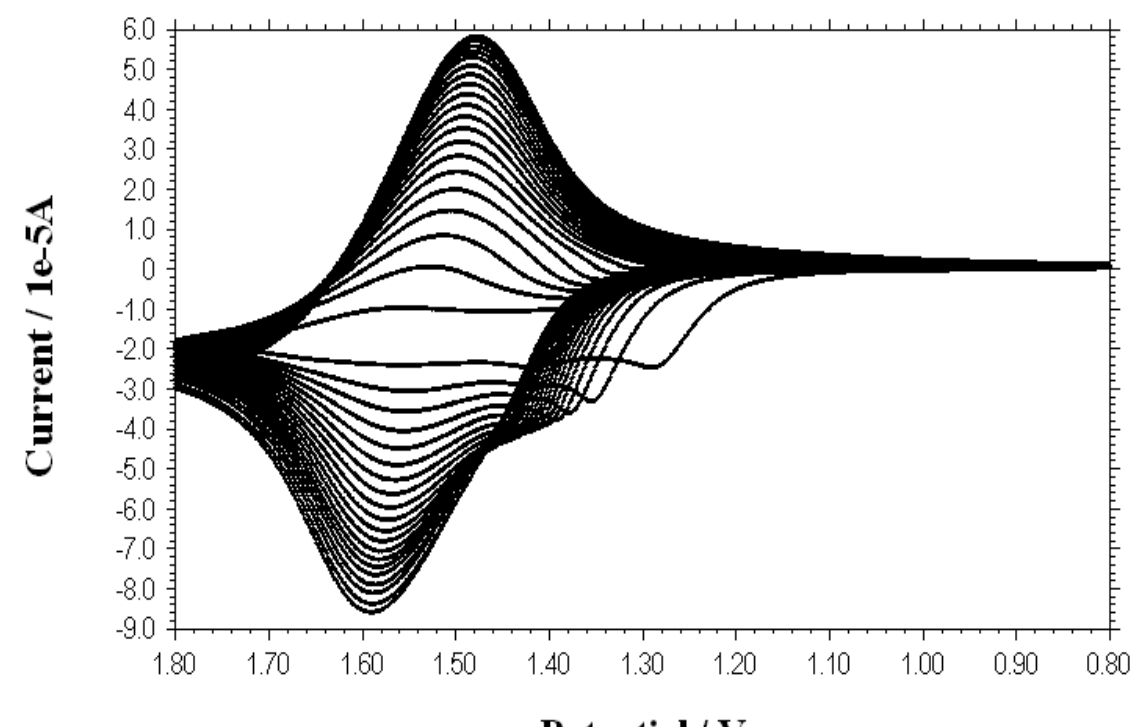

Potential / V

Figure 3. Representative electropolymerization of $1.00 \times 10^{-3} \mathrm{M} \mathrm{Ru}\left(5-\mathrm{phenNH}_{2}\right)_{3}\left(\mathrm{PF}_{6}\right)_{2}$. Supporting electrolyte is $0.100 \mathrm{M}$ TEAP and solvent is acetonitrile. Scan Rate $=0.05 \mathrm{~V} / \mathrm{sec}$. Twenty cycles of electropolymerization from $1.800 \mathrm{~V}$ to $0.800 \mathrm{~V}$ 


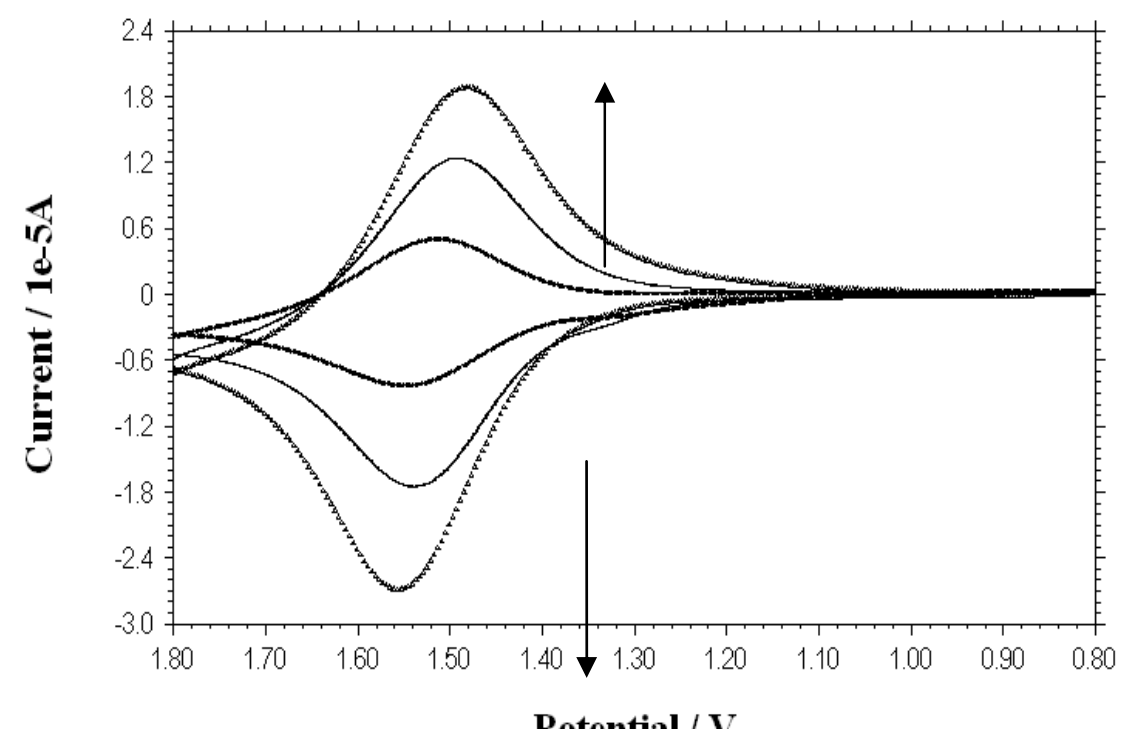

Potential / V

Figure 4. Representative characterization of ruthenium polymer films. Cyclic voltammograms based on: (A-Bottom) 5, (B-Middle) 10, and (C-Top) 20 cycles of electropolymerization of $1.00 \times 10^{-3} \mathrm{M}$ $\mathrm{Ru}\left(5-\mathrm{phenNH}_{2}\right)_{3}\left(\mathrm{PF}_{6}\right)_{2}$ in $0.100 \mathrm{M}$ TEAP in acetonitrile at a $0.01 \mathrm{~V} / \mathrm{sec}$ scan rate from $1.800 \mathrm{~V}$ to $0.800 \mathrm{~V}$

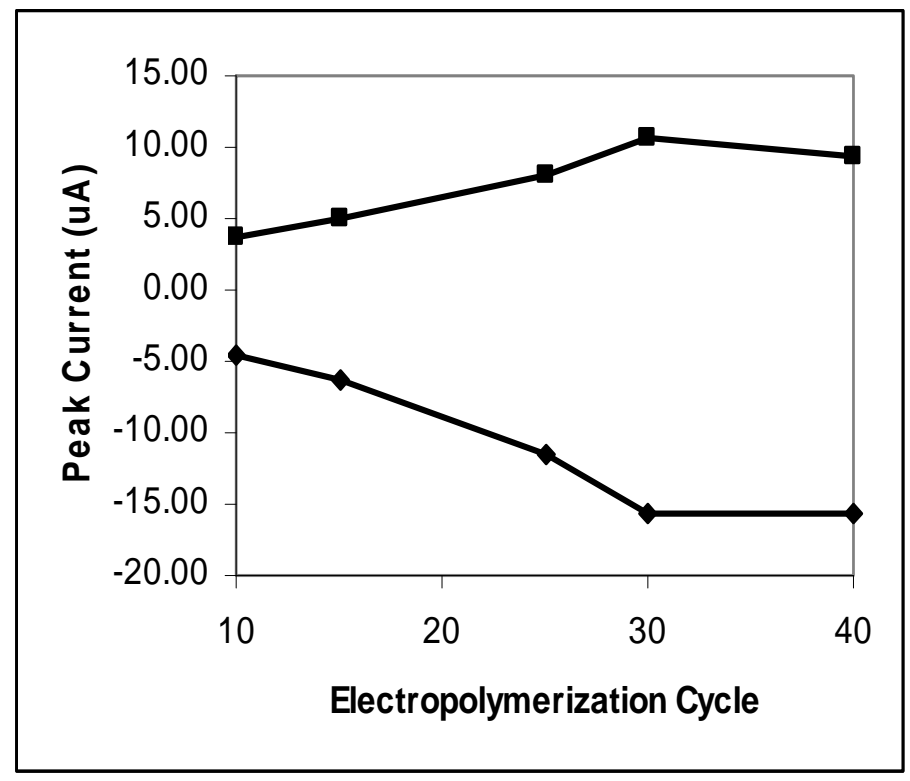

Figure 5. Anodic and cathodic peak currents in characterization of ruthenium polymer film corresponding to different cycles of electropolymerization. Electropolymerization was completed in $5.00 \times 10^{-4} \mathrm{M}$ $\left.\mathrm{Ru}(5-\text { phenNH })_{3}\right)_{3}\left(\mathrm{PF}_{6}\right)_{2}$ in supporting electrolyte $(0.050 \mathrm{M}$ TEAP in acetonitrile) 


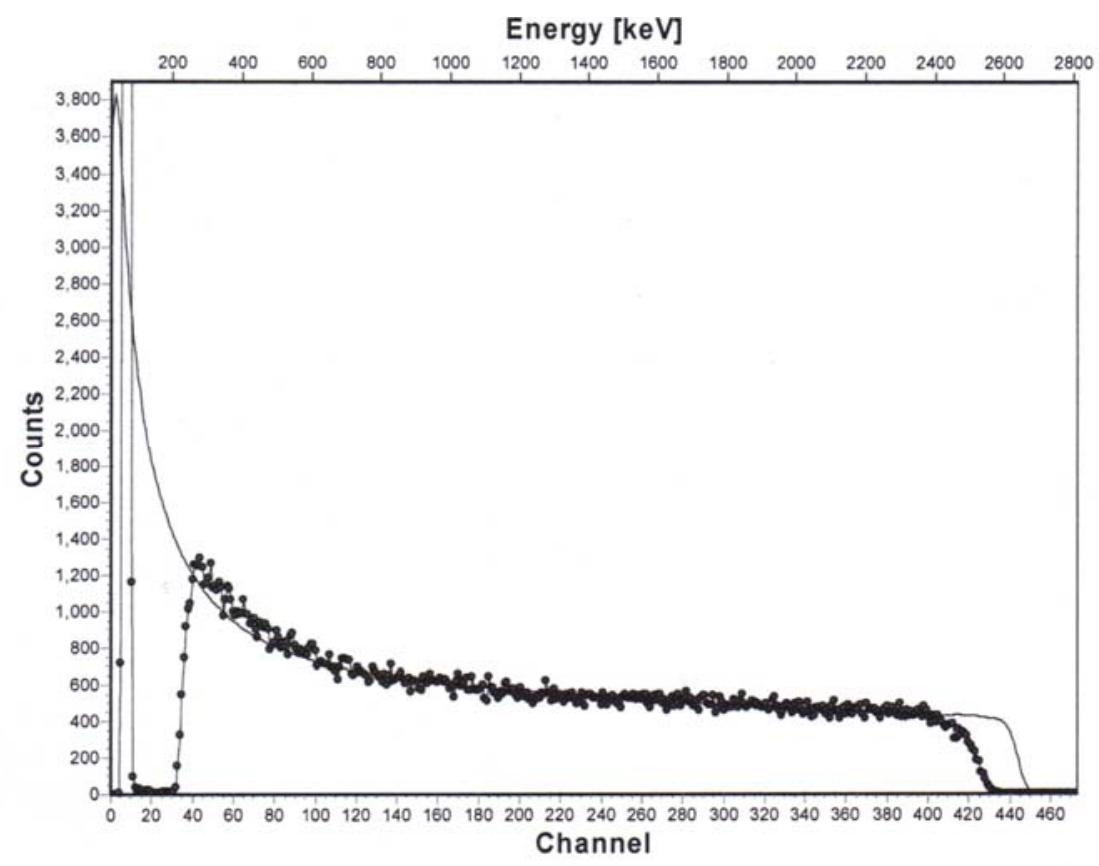

Figure 6. A representative RBS spectrum of a ruthenium polymer film on a platinum electrode. Film was generated from 10 cycles and 25 cycles of electropolymerization in $1.00 \times 10^{-3} \mathrm{M} \mathrm{Ru}\left(5-\mathrm{phenNH}_{2}\right)_{3}\left(\mathrm{PF}_{6}\right)_{2}$ in supporting electrolyte $(0.100 \mathrm{M}$ TEAP). Front edge at $2720 \mathrm{keV}$ represents the 10 cycle film

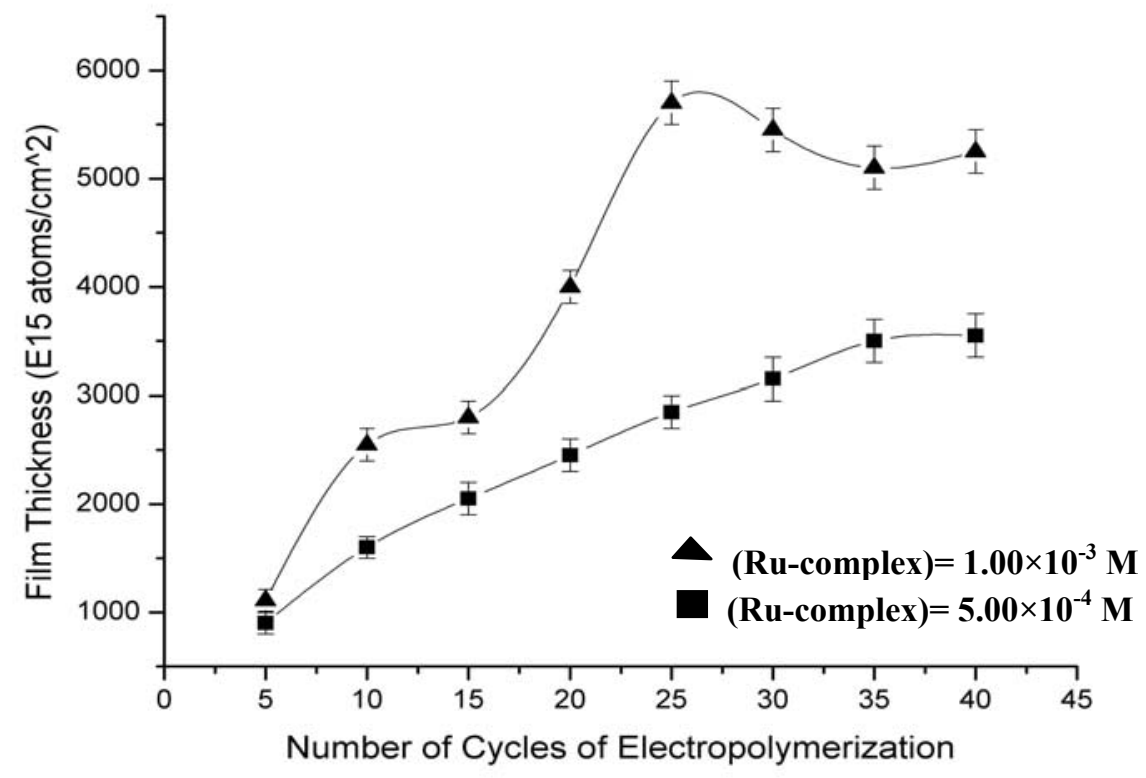

Figure 7. The variation of ruthenium polymer film thickness with respect to electropolymerization cycles at two different concentrations of Ru-complex solution 